\title{
肥大船の波浪中抵抗増加推定法 に関专実験的研究
}

\author{
正員 藤 井 斉* 正員高 橋 雄* \\ Experimental Study on the Resistance Increase of a Large \\ Full Ship in Regular Oblique Waves \\ by Hitoshi Fujii, Member Takeshi Takahashi, Member \\ Summary
}

An attempt has been made to establish an approximate method to calculate the resistance increase of a full ship in regular oblique waves. Applicability of this method was confirmed by the model test carried out in regular oblique waves making use of a newly designed dynamometer.

Comparing the measured resistance increase and the computed one in accordance with the slender body assumption, fairly good agreement is shown as a whole except for the range of shorter wave length where the measured value is larger than the computed one. An approximate calculation method was proposed in consideration of the resistance increase due to the wave reflection at the blunt bow.

It was shown that total resistance increase of a full ship in waves can be obtained approximately by the sum of the resistance due to ship motions and the wave reflection at the bow.

\section{1 緒言}

波浪中に拈ける船舶の推進性能を推定することは，耐航性能の研究に括ける重要な課題の1つであるが，これ までは主として実験的な手法，例えば推力増加の計測といらような形で研究が進められてきた。しかしながら最 近の造波理論に関する研究の進歩により,波浪中の抵抗増加について理論計算が可能となったので,これとプロぺ ラ特性および自航要素等を組合せることによって, 波浪中に特ける推進性能を推定計算する途がひらけてきた。

正面向波中の抵抗増加に関しては，理論的にも実験的にもこれまでにかなり研究が進められて扣り ${ }^{1,2)}$, 著者 等3) b丸尾の理論に従って近似計算を行ない, 実験結果と比較して計算法の適用性を調査してきた。斜め波中の 抵抗増加に関しても，細田 ${ }^{4}$ の研究により「斜め波中の抵抗増加に対しては，上下摇れ拈よび縦摇れの寄与が支 配的であり，横運動の奇与は小さい。」といことが示されたので，これに従って正面向波中の抵抗増加の計算 法を斜め波中に拡張し，斜め波中の抵抗増加を計算する計算プログラムを作成した。この斜め波中の抵抗増加の 計算法の適用性は水槽試験によって確認する必要があるので, 斜め波中試験に用いることのできる重錘式抵抗動 力計を試作して，抵抗増加の計測を試みた。斜め波中の抵抗増加の計測はこれまでほとんど行なわれたことがな く，確立した試験法はまだないよらである。ここで実施した試験法も十分なるのとはいえないが，ほぼその目的 に適ったものであると考えられる。

波浪中に拈ける抵抗増加についてのこれまでの理論計算は，主として船体運動に基づく量を計算しており，波 に対する上下方向の相対速度に比例する強さの特異点によって船体による鲵乱効果を表わしている。したがって 波長の短かい場合は, 船体運動も小さくかつ船底付近では波粒子の軌道運動も小さいので, 抵抗増加は少ないこ とになる。事実, 癒型船型に関する模型試験の結果はこのような理論的考察の裏付けを示している。ところが船 首部の blunt な大型肥大船に関する模型試験の結果では, 船体運動のほとんどない短波長域 $(\lambda / L \leqq 0.5) に$ に

\footnotetext{
* 三菱重工業(株)長崎研究所
} 
てかなりの量の抵抗増加が認められ，その大きさは抵抗増加の応答関数の上で船体運動の大きい場合の抵抗増加 の $1 / 2$ あるいはそれ以上にも達している。最近のタンカーはますます大型化の傾向にあるが，それに伴って実際 海面で遭遇する波長が相対的に短くなってきて扣り，この上らな短波長域に括ける抵抗增加が，波浪中に挌ける 推進性能上の 1 つの重要な問題となりつつある。

船首部の blunt な大型肥大船の短波長域で顕著に見られるこのような抵抗增加は，これまでの計算法には十 分表わされていなかった船首部船側からの反射波に基づくものと考兄られる。そこでこの量を実用的な立場で近 似的に評価し, 肥大船の抵抗増加の推定をより精度よくするため, Havelock の drifting force に関する計算式 を基礎として近似的に計算し，これまでの船体運動に基づく抵抗増加に単純に加え合せることによって肥大船の 波浪中抵抗増加を推定計算することを試みた。

最近の超大型船の船首部はますます肥大化の傾向にあるが，その形状の決定に際しては平水中性能だけでなく， 波浪中に特ける抵抗增加や船首波浪衝撃あるいは投錨など多方面から検討を加光る必要があると考兄られる。

\section{2 斜め波中の抵抗增加の計算式}

\section{1 船体運動に基づく抵抗增加}

斜め規則波中に捛ける船体の抵抗增加 $R_{A W(0)}$ は，丸尾帛により次のように与兄られている。

$$
R_{A W(0)}=4 \pi \rho\left[-\int_{-\infty}^{a_{1}}+\int_{a_{2}}^{\infty}\right] \frac{\left(m+K_{0} \Omega\right)^{2}(m-k \cos \mu)}{\sqrt{\left(m+K_{0} \Omega\right)^{4}-K_{0}^{2} m^{2}}}\left|H_{1}(m)\right|^{2} d m
$$

たたし

$$
\begin{aligned}
& k=2 \pi / \lambda \quad g: \text { 重力加速度 } \\
& C^{2}=g / k \quad \lambda: \text { 波長 } \\
& \omega_{e}=k(C-U \cos \mu) \quad U \text { : 前進速度 } \\
& K_{0}=g / U^{2} \quad \omega_{e} \text { : 出合い円周波数 } \\
& \Omega=U\left|\omega_{e}\right| / g \quad \mu: \text { 波方向 } \\
& \left.\begin{array}{l}
a_{1} \\
a_{2}
\end{array}\right\}=-\frac{K_{0}}{2}(1+2 \Omega \pm \sqrt{1-4 \Omega})
\end{aligned}
$$

$H_{1}(m)$ は特異点分布によって決まる関数であるが, 近似的な取扱いとして船体を細長体と仮定し, 船体の各 䉼面で波に対する上下方向の相対速度に比例する強さの吹出し $\sigma(x)$ を船長方向に一定の深さ $Z_{\sigma}=-C_{V P} T_{\mathbf{0}}$ ( $C_{V P}$ : 堅柱形肥㾑係数, $T_{0}$ ：契水）飞集中させるるのとすれば，次のように表わされる。

$$
H_{1}(m)=\int\left(\sigma_{c}-i \sigma_{s}\right) e^{\frac{\left(m+K_{0} \Omega\right) 2}{k} Z_{\sigma}+i m x} d x
$$

ただし

$$
\begin{aligned}
\sigma=\sigma_{c} \cos \omega_{e} t+\sigma_{s} \sin \omega_{e} t & =-\frac{1}{4 \pi}\left(\frac{\partial}{\partial t}-U \frac{\partial}{\partial x}\right)\left\{Z_{r}(x) \cdot y(x)\right\} \\
Z_{r}(x) & =Z+\left(x-x_{G}\right) \theta-\zeta_{s u b}
\end{aligned}
$$

$Z_{r}(x)$ : 各横断面に括ける波に対する上下方向相対変位

$y(x)$ : 各横断面の水線幅

$Z$ : 上下摇れ变位, $Z=Z_{A} \cos \left(\omega_{e} t+\varepsilon_{z}\right)$

$\theta:$ 縦摇孔角, $\theta=\theta_{A} \cos \left(\omega_{e} t+\varepsilon_{\theta}\right)$

$x, x_{G}:$ 船体の長さ力向座標值执よび重心位置

$\zeta_{\text {sub }}:$ 波の subsurface の変位

$$
\zeta_{\text {sub }}=h_{A} e^{k Z \sigma} \cos \left(k x \cos \mu-\omega_{e} t\right)
$$

抵抗增加係数の無次元表示を $\sigma_{A W(0)}$ とすれば， $\sigma_{A W}(0)$ は次のように船体運動挌よび入射波の影響による成分 の和として表わすことができる。

$$
\sigma_{A W(0)}=\frac{R_{A W(0)}}{\rho g h^{2}{ }_{A} B^{2} / L}=D_{11} \hat{z}_{A}{ }^{2}+D_{22} \hat{\theta}_{A}{ }^{2}+D_{33}+D_{12} \hat{z}_{A} \hat{\theta}_{A}+D_{13} \hat{z}_{A}+D_{23} \hat{\theta}_{A}
$$

ただし，係数 $D_{l j}$ の添字は，1：上下摇れに関する量， 2 : 緥摇れに関する量， 3 : 波に関する量を示す。 
係数 $D_{i j}$ は次のような中間積分值 $S(\hat{x}), C(\hat{x})$ を用いて表わすことができる。

$$
\left.\begin{array}{l}
S(\hat{x}) \\
C(\hat{x})
\end{array}\right\}=\int_{\hat{m}} M\left\{\begin{array}{l}
\sin (\hat{m} \hat{x}) \\
\cos (\hat{m} \hat{x})
\end{array}\right\} d \hat{m}
$$

ただし

$$
\begin{aligned}
& M=\frac{1}{2 \pi \hat{K}_{0}} \frac{\left(\hat{m}+\hat{\omega}_{e}\right)^{4}(\hat{m}-\hat{k} \cos \mu)}{\sqrt{\left(\hat{m}+\hat{\omega}_{e}\right)^{4}-\left(\hat{K}_{0} \hat{m}\right)^{2}}} e^{-\frac{2 C_{V P}\left(\hat{m}+\hat{\omega}_{e}\right)^{2}}{\hat{K}_{0}}} \\
& D_{11}=\iint \hat{y} \hat{y}^{\prime} C\left(\hat{x}-\hat{x}^{\prime}\right) d \hat{x} d \hat{x}^{\prime} \\
& D_{22}=\hat{k}^{2} \iint \hat{y} \hat{y}^{\prime}\left(\hat{x}-\hat{x}_{G}\right)\left(\hat{x}^{\prime}-\hat{x}_{G}\right) C\left(\hat{x}-\hat{x}^{\prime}\right) d \hat{x} d \hat{x}^{\prime} \\
& D_{33}=e^{-2 C_{V} P \hat{k} \hat{T}_{0}} \iint \hat{y} \hat{y}^{\prime}\left[C\left(\hat{x}-\hat{x}^{\prime}\right) \cos \left\{\hat{k}\left(\hat{x}-\hat{x}^{\prime}\right) \cos \mu\right\}+S\left(\hat{x}-\hat{x}^{\prime}\right) \sin \left\{\hat{k}\left(\hat{x}-\hat{x}^{\prime}\right) \cos \mu\right\}\right] d \hat{x} d \hat{x}^{\prime} \\
& D_{12}=D_{12}{ }^{C} \cos \left(\varepsilon_{Z}-\varepsilon_{\theta}\right)+D_{12} s \sin \left(\varepsilon_{Z}-\varepsilon_{\theta}\right) \\
& \left.\begin{array}{l}
D_{13}=D_{13}{ }^{c} \cos \varepsilon_{Z}+D_{13} s \sin \varepsilon_{Z} \\
D_{23}=D_{23}{ }^{c} \cos \varepsilon_{\theta}+D_{23} s \sin \varepsilon_{\theta}
\end{array}\right\} \text { 詳細な式は省略する。 }
\end{aligned}
$$

ただし，上式に打いて次のような無次元表示を用いている。

$$
\begin{array}{ll}
\hat{Z}_{A}=Z_{A} / h_{A}, & \hat{\theta}_{A}=\theta_{A} / k h_{A}, \quad \hat{k}=k /(2 / L), \quad \hat{K}_{0}=K_{0} /(2 / L), \quad \hat{m}=m /(L / 2), \quad \hat{\omega}_{e}=\hat{K}_{0} \Omega, \\
\hat{x}=x /(L / 2), & \hat{x}_{G}=x_{G} /(L / 2), \quad \hat{y}=y / B, \quad \hat{T}_{0}=T_{0} /(L / 2)
\end{array}
$$

ところで，この波浪中抵抗増加の計算式は 3 重積分で表示されており，しかも積分区間が無限区間であったり 被積分関数が発散したりするため, 複雑な数值積分となる。そのため電算機を使用してるかなりの計算時間と費 用を要する。しかしながら実用上は必ずしも任意の波長，任意の船速で抵抗増加が計算できる必要はなく，特定 の波長や船速に対して計算できれば，抵抗増加の応答関数は比較的単純な形をしているので，ほぼその形を定め ることができる。抵抗増加計算の中間積分值 $S(\hat{x}), C(\hat{x})$ は, 波方向 $(\mu)$, 波長 $(\lambda / L)$, 船速 $\left(F_{n}\right)$, 船体座標 $(\hat{x})$, 特異点の深さ位置 $\left(C_{V P} \hat{T}_{0}\right)$, の 5 個のパラメータによって決定される。したがってあらかじめこれらのパ ラメータに対して一度広範囲に $S(\hat{x}), C(\hat{x})$ を計算して作表して特けば，以後はその数值表を呼出しながら短時 間で抵坑増加を計算することができる。

\section{2 従来の計算法による抵抗增加の計算値と実験值の比較}

このようにして, 細長体の仮定により波浪中の抵抗増 加が計算でさるが，この計算法を肥大船に適用すると $\lambda / L=0.7$ 以下の短波長域で, 計算值は実験值よりもか なり小さな值を示す。Fig. 1 は Series $60, \mathrm{Cb}=0.8$ 船 型についての計算值と実験值の比較図で, 実験結果は参 考文献 6) の Fig. 17 より転記した。計算值は $\sigma_{A W(0)}$ と その成分の 1 つ $D_{33}$ を示している。この $D_{33}$ は反射波 影響を示す項であるが，この項は船体を細長体と仮定し て主として船底に和ける波に対する筧乱効果を表わした ものであり，船体運動の小さい短波長域ではこの項が主 要項となっている。この図にも見られるように短波長域 で計算值は実験值よりも小さな值を示しており，これま での計算法には表わされていない要素があるのではない かと考光られる。

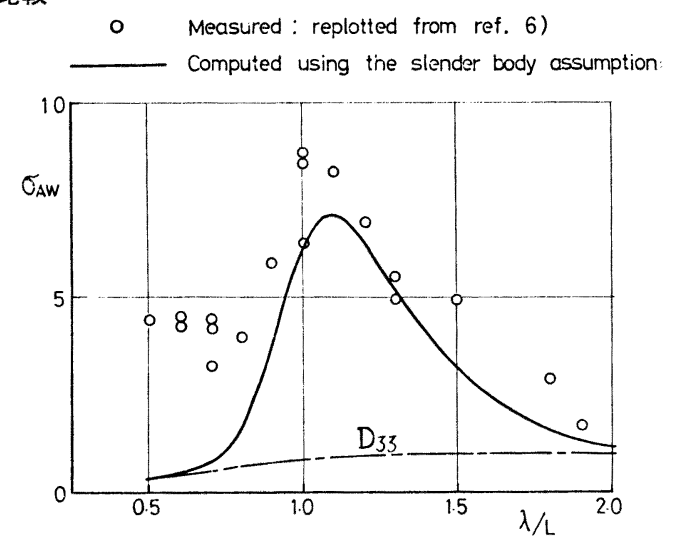

Fig. 1 Resistance increase of Series 60 $\mathrm{Cb}=0.8$ model

\section{3 肥大船の波浪中抵抗增加の近似計算法}

肥大船に対して短波長域で顕著にみられるこのような抵抗増加の原因は，blunt な船首部からの反射波に基ら く抵抗增加が大きいためと考光られる。特異点分布によって決まる関数 $H_{1}(m)$ を船首部船側る含めて船体表面 の境界条件を満たすように決めることができるならば，このような反射波に基づくと考えられる抵抗增加も理論 的に戦密に計算することができると考兄られる。しかしながら, 実際上それは相当にむつかしい問題であるため, 船体を細長体と仮定するなどして近似的な計算が行なわれている。従来から行なわれている抵抗増加の計算は前 
述のように主として船体運動に基づくものであるので，これに船首部からの反射波に基づく抵抗増加を単純に加 兄合せて，昍大船の波浪中抵抗増加を次のような形で推定することを試みた。

$$
R_{A W}=R_{A W(0)}+R_{A W(1)}
$$

$R_{A W(0)}$ : 船体運動に基づく抵抗增加

$R_{A W(1)}$ : 船首部からの反射波に基つくく抵抗增加

\section{4 船首部からの反射波に基づく抵抗增加}

船首部からの反射波に基づく抵抗増加を厳密に計算することは，かなりむつかしい問題であるためここでは近 似的な計算法を用いることにする。直立した筒体に作用する漂流力については別所 はもっと簡単に波長が無限小の場合の極限值である Havelock の drifting force の計算式を基碟にして, 極く 実用的な立場で船首部からの反射波に基づく抵抗増加を評価することとした。

波長の極めて短かい波の中に直立した柱状体に作用する drifting force は, Havelock $\left.{ }^{5}\right)$ にって次のように 与えられている。

$$
D=\frac{1}{2} \rho g h_{A}^{2} \int_{-B / 2}^{B / 2} \sin ^{2} \beta d y
$$

これは Fig. 2 に示すように， $x$ 軸と傾斜 $\beta$ をなす物体の表面に入射した波が， $x$ 軸と $2 \beta$ 方向に完全に反射さ れたとしてその間の運動量变化から求められる。 $\overline{\sin ^{2} \beta}=\frac{1}{B} \int_{-B / 2}^{B / 2} \sin ^{2} \beta d y$ は, drifting force に対する船首部 肥大度の影響の大きさを与える 1 つのパラメータであるのでこれを bluntness 係数と呼ぶことにする。

（8）式を用いて抵抗增加を推定するには，有限契水の影響牞よび前進速度の影響を取入れなければならない。 この影響を表わす修正係数をとれぞれ $\alpha_{1}, \alpha_{2}$ として，船首部からの反射波に基づく抵抗増加は次のよらな形で 表わされるものと仮定する。

$$
R_{A W(1)}=\alpha_{1}\left(1+\alpha_{2}\right) \frac{1}{2} \rho g h_{A}^{2} B \overline{\sin ^{2} \beta}
$$

ここで， $\alpha_{1}$ そついては vertical barrier の反射率 $R$ の 2 乗を用いることとし， $\alpha_{2}$ とつては実験式を用いる こととした。すなおち

$$
\left.\begin{array}{ll}
\alpha_{1}=R^{2}=\pi^{2} I_{1}^{2} /\left(\pi^{2} I_{1}^{2}+K_{1}^{2}\right), & I_{1}=I_{1}(k d) \\
\alpha_{2}=5 \sqrt{F_{n}} & K_{1}=K_{1}(k d)
\end{array}\right\} \text { 变形ベッセル関数 }
$$

な怙，斜め波の場合には波方向を考慮に入れた $\overline{\sin ^{2} \beta}$ を用いなければならない。Fig. 3 は肥大船の抵抗増加の 応答関数に対する $R_{A W(0)}$ と $R_{A W(1)}$ の寄与の割合を概念的に示したものである。

\section{3 水 槽 試 験}

水槽試験は三菱重工業(株)長崎研究所の耐航性能水槽（長さ $160 \mathrm{~m} \times$ 幅 $30 \mathrm{~m} \times$ 深さ $3.5 \mathrm{~m}$ ）で実施した。

\section{1 斜め波中用重鍾式抵抗動力計}

斜め波中の抵抗增加計測用として試作した重錘式抵抗動力計の概念図をFig. 4 に示す。このような方式は横 運動に対して全く影響がないわけではないが，波浪中の抵抗増加には縃運動の影響が支配的であることを考える とこの動力計で泳正しく抵抗增加が計測されているものと考兄られる。斜め波中試験は XY 曳引車を指定さ れた方向特よび速度で運転し, 模型船を指定の方位に保って曳航した。

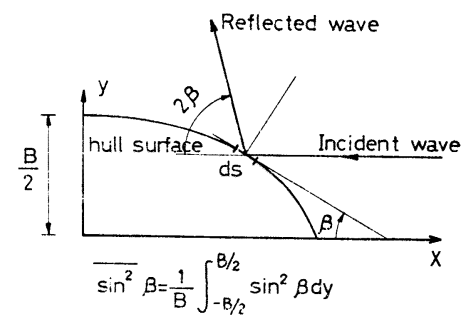

Fig. 2 Wave reflection and the bluntness coefficient

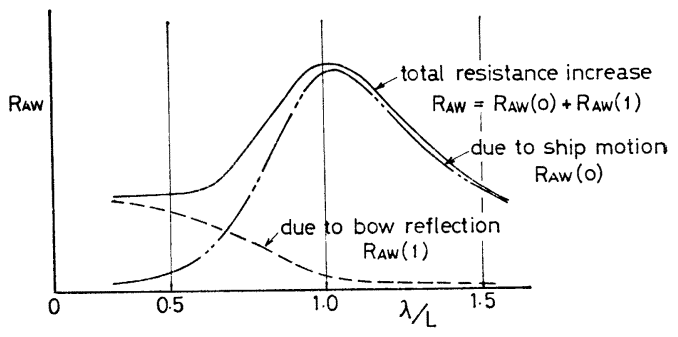

Fig. 3 Components of the resistance increase of a full ship 


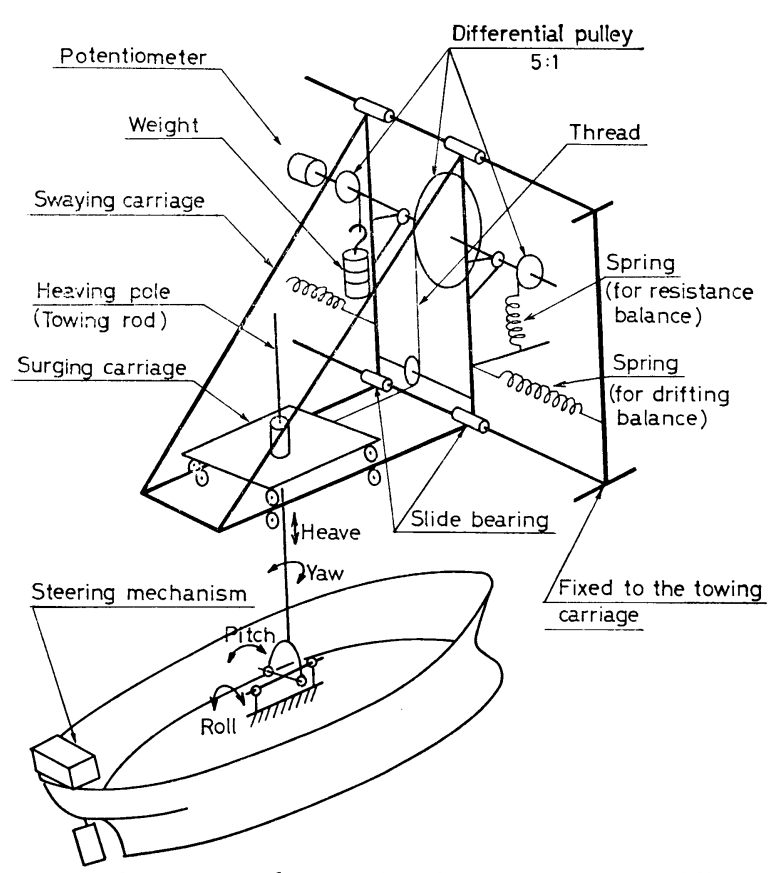

Fig. 4 Scheme of the gravity dynamometer for oblique wave test
Table 1 Principal particulars of the tested model

\begin{tabular}{|c|c|c|}
\hline & & Tariker \\
\hline Length & L & $3.000 \mathrm{~m}$ \\
\hline Brsadth & $B$ & $546.44 \mathrm{~mm}$ \\
\hline Draft & $d$ & $216.22^{\mathrm{mm}}$ \\
\hline Displacement & $\Delta a$ & $299.99 \mathrm{~kg}$ \\
\hline Block coeff. & $\mathrm{Cb}$ & 0.8464 \\
\hline Water plane area cceff. & $C \cdot N$ & 0.9200 \\
\hline L.C.B. & & $46621 \%$ \\
\hline Longitudinal gyradius & $k_{y y} / L$ & 0.228 \\
\hline Metacentric height & $G+1$ & $81.6 \mathrm{~mm}$ \\
\hline Rolling period & $T \phi$ & $1.42^{\mathrm{sec}}$ \\
\hline
\end{tabular}

\section{2 供試模型船および試験条件}

（1）船首肥大度シリーズ試験

短波長域に沶ける抵抗増加之船首肥大度の 関係を調査するため, Fig. 5 に示すよらな bluntness 係数 $\overline{\sin ^{2} \beta}$ を種々変更した模型 船について, 正面向波 $\left(\mu=180^{\circ}\right)$ の短波長域 で抵抗増加の計測を行なった。

（2）タンカーの斜め波中試験

超大型タンカーの模型船について斜め波中 の抵抗増加を計測した。模型船の主要目を Table 1 に示す。波方向は $\mu=180^{\circ} \sim 135^{\circ}$ の範囲で $15^{\circ}$ 毎に, 波 長は $\lambda / L=0.3 \sim 1.5$, 波高は $h_{W} / L=1 / 75$ で実施した。

\section{4 計算值と実験値の比較}

\section{1 船首部からの反射波に基づく抵抗增加}

船首肥大度をシリーズに変更した 4 隻の肥大船型模型の短波長正面向波に括ける波浪中抵抗増加係数の一例を

\begin{tabular}{|c|c|c|}
\hline$\overline{\sin ^{2} \beta}$ & Water line & Measured \\
\hline 0.592 & - & $\square$ \\
\hline 0.438 & - & - \\
\hline 0.356 & -- & $\Delta$ \\
\hline 0.292 & --- & 0 \\
\hline
\end{tabular}
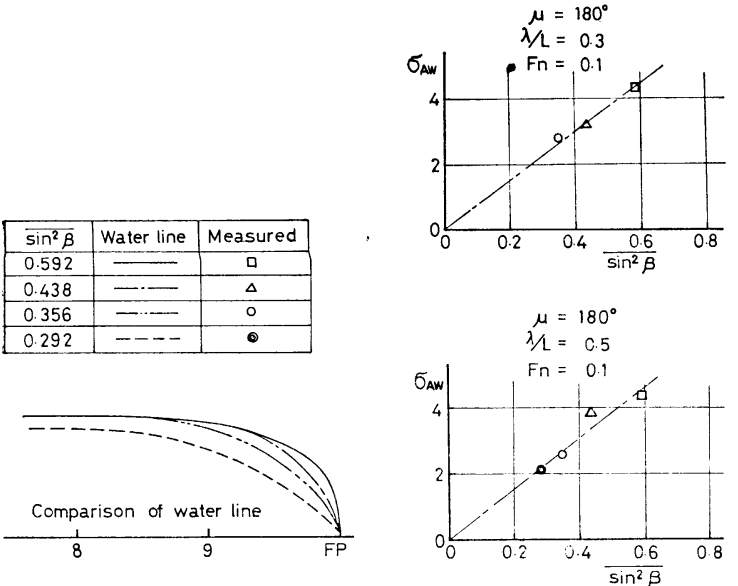

Fig. 5 Correlation between the bluntness and the resistance increase in shorter wave length range

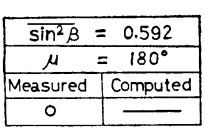

(a) Effect of draft

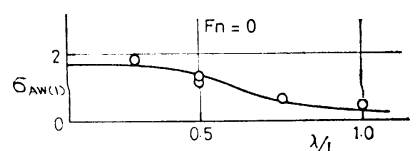

(b) Effect of advance speed

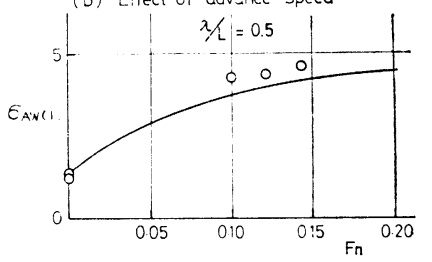

Fig. 6 Effect of draft and advance speed on the resistance increase due to bow reflection 


\begin{tabular}{|c|c|l|}
\hline Fn & Measured & Computed \\
\hline \multirow{2}{*}{0.12} & \multirow{2}{*}{$\circ$} & $\sigma_{\text {AW }}$ \\
\cline { 3 - 3 } & & $\sigma_{A W}(0)$ \\
\hline
\end{tabular}
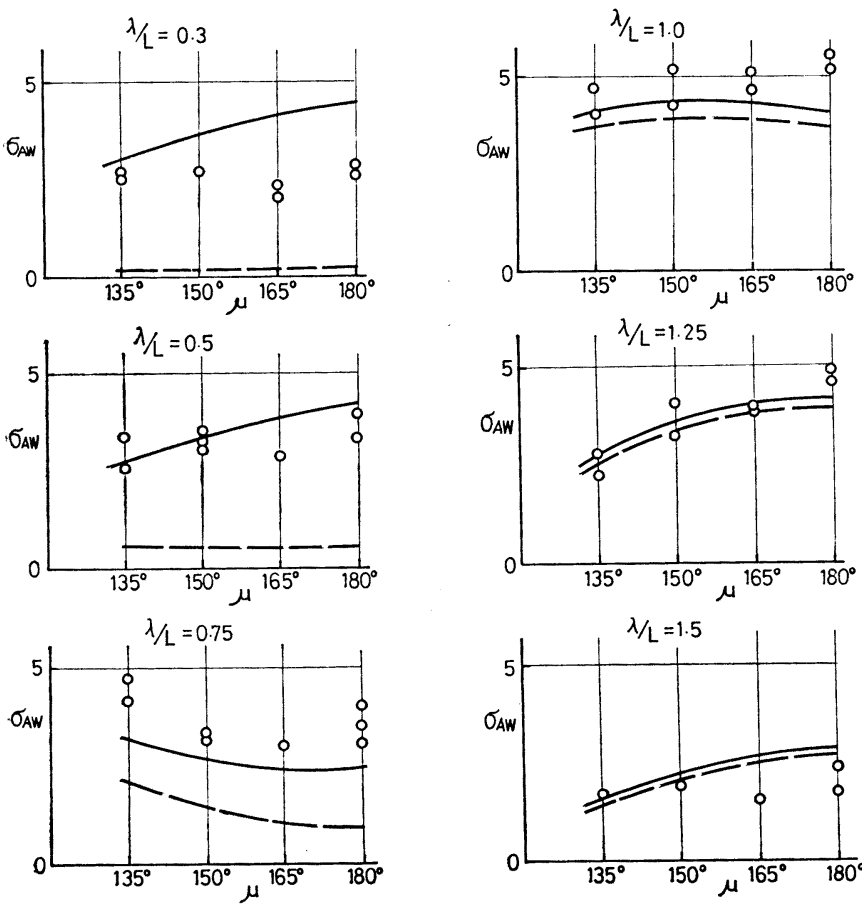

Fig. 7 Measured and computed resistance increase in oblique waves for a tanker model
Fig. 5 に示す。この図に見られるよ らに抵抗増加係数は $\overline{\sin ^{2} \beta}$ にほぼ 比例して和り, $\overline{\sin ^{2} \beta}$ は抵抗增加に 対する船首肥大度の影響を示すパラ メータとして妥当なものであると考 えられる。Fig. 6 は有限契水の影響 と前進速度の影響について実験值と （9）式による計算値とを比較したる ので，この図に見られるように船首 部からの反射波に基づく抵抗増加は (9)式によってほぼ近似し得るるの と考えられる。

\section{2 斜め波中の抵抗増加}

超大型タンカーの模型船の斜め波 中に拈ける抵抗増加の実験值を計算 值と比較して Fig.7 に示す。実験 結果を見ると $\lambda / L=1.0,1.25,1.5$ では斜め波の方が抵抗増加が少なく なる傾向にあるが, $\lambda / L=0.75$ では $\mu=180^{\circ}$ よりも $\mu=135^{\circ}$ の方が抵 抗増加が大きくなっている。これは

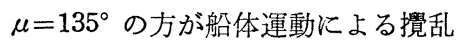
の度合が大きいためと考えられる。 $\sigma_{A W(1)}$ を加えた計算結果は $\lambda / L=$ 0.5 1.5 の範团でオーダーおよび

傾向とるに実験結果に近くここに示した計算法によって肥大船の抵抗増加を大略推定し得ると考えられる。

\section{5 結言}

肥大船の波浪中に和ける抵抗増加に沶いて波長の短い場合に見られる比較的大きな抵抗増加は, blunt な船首 部からの反射波に基づくものと考光，これを從来から計算されている船体運動に基づく抵抗増加に加え合せるこ とによって肥大船の抵抗増加が注ぼ推定できることを示した。この方法は実験結果を参照しつつ実用的な立場で 求めた極く近似的な方法であるので, 今後この量を理論的に正しく計算してみなければならない。また斜め波中 の抵抗増加を計測することを試みたが, 試験法としても確立されたものではないので, これについてもさらに検 討を加える必要がある。

終りに, この研究の実施にあたり実験および解析に尽力いただいた三菱重工業(株)長崎研究所耐航性能水槽の 朝長義英氏はじめ実験室の諸氏，ならびに電算プログラムの作成にあたった貞包令子嬢に感謝する。

\section{参 考 文 献}

1) 丸尾 孟: Resistance in Waves, Researches on Seakeeping Qualities of Ship in Japan, Chap. 5, 造船協会 60 周年記念叢書, Vol. 8, (昭和 38 年).

2) Gerritsma, J. and Beukelman, W.: Analysis of the Resistance Increase in Waves of a Fast Cargo Ship, I. S. P., Vol. 19, No. 217, (Sept. 1972).

3）藤井 斉, 高橋 雄: 正面規則波中に拈ける抵抗増加, 三菱重工技報, 第 4 巻, 第 6 号, (昭和 42 年 11 月).

4) 細田龍介：斜波中注ける船体抵抗増加に関する研究，造船学会論文集第 133 号，(昭和 48 年 6 月).

5) Havelock, T.H.: The Pressure of Water Waves upon a Fixed Obstacle, P. R. S. Series A, No. 963, Vol. 175, (July, 1940).

6) Strom-Tejsen, J., Yeh, H. Y.H. and Moran, D. D.: Added Resistance in Waves, T. S. N. A. M. E. Vol. 81, (1973).

7）別所正利：固定筒体に及ぼす波の王力について，造船協会論文集第 101 号，(昭和 32 年 8 月），同（続報）, 同第 102 号, (昭和 33 年 2 月), 同 (第 3 報), 同第 103 号, (昭和 33 年 7 月). 